\title{
Six weeks of high-intensity interval training enhances contractile activity induced vascular reactivity and skeletal muscle perfusion in older adults
}

\author{
Philip J. J. Herrod • Philip J. Atherton • \\ Kenneth Smith • John P. Williams • \\ Jonathan N. Lund • Bethan E. Phillips
}

Received: 6 July 2021 / Accepted: 18 September 2021 / Published online: 25 September 2021

(C) The Author(s) 2021

\begin{abstract}
Impairments in muscle microvascular function are associated with the pathogenesis of sarcopenia and cardiovascular disease. High-intensity interval training (HIIT) is an intervention by which a myriad of beneficial skeletal muscle/cardiovascular adaptations have been reported across age, including capillarisation and improved endothelial function. Herein, we hypothesised that HIIT would enhance muscle microvascular blood flow and vascular reactivity to acute contractile activity in older adults, reflecting HIIT-induced vascular remodelling. In a randomised controlled-trial, twenty-five healthy older adults aged 65-85 years (mean BMI 27.0) were randomised to 6-week HIIT or a nointervention control period of an equal duration. Measures of microvascular responses to a single bout of muscle contractions (i.e. knee extensions)
\end{abstract}

P. J. J. Herrod · P. J. Atherton · K. Smith · J. P. Williams ·

J. N. Lund · B. E. Phillips $(\varangle)$

Medical Research Council-Versus Arthritis Centre

for Musculoskeletal Ageing Research, University

of Nottingham, Royal Derby Hospital Centre,

DE22 3DT Derby, UK

e-mail: beth.phillips@nottingham.ac.uk

P. J. J. Herrod · P. J. Atherton · K. Smith - J. P. Williams · J. N. Lund · B. E. Phillips

NIHR Nottingham Biomedical Research Centre, Queens

Medical Centre, Nottingham, UK

P. J. J. Herrod · J. P. Williams · J. N. Lund

Department of Anaesthetics and Surgery, Royal Derby

Hospital, Derby, UK were made in the $m$. vastus lateralis using contrastenhanced ultrasound during a continuous intravenous infusion of Sonovue ${ }^{\mathrm{TM}}$ contrast agent, before and after the intervention period, with concomitant assessments of cardiorespiratory fitness and resting blood pressure. HIIT led to improvements in anaerobic threshold $(13.2 \pm 3.4$ vs. $15.3 \pm 3.8 \mathrm{ml} / \mathrm{kg} / \mathrm{min}$, $\mathrm{P}<0.001)$, dynamic exercise capacity $(145 \pm 60$ vs. $159 \pm 59 \mathrm{~W}, \mathrm{P}<0.001)$ and resting (systolic) blood pressure $(142 \pm 15$ vs. $133 \pm 11 \mathrm{mmHg}, \mathrm{P}<0.01)$. Notably, HIIT elicited significant increases in microvascular blood flow responses to acute contractile activity $(1.8 \pm 0.63$ vs. $2.3 \pm 0.8$ (arbitrary contrast units (AU), $\mathrm{P}<0.01)$ ), with no change in any of these parameters observed in the control group. Six weeks HIIT improves skeletal muscle microvascular responsiveness to acute contractile activity in the form of active hyperaemia-induced by a single bout of resistance exercise. These findings likely reflect reports of enhanced large vessel distensibility, improved endothelial function, and muscle capillarisation following HIIT. Moreover, our findings illustrate that HIIT may be effective in mitigating deleterious alterations in muscle microvascular mediated aspects of sarcopenia.

Keywords High-intensity interval training Ageing - Exercise - Microvascular blood flow Skeletal muscle 


\section{Abbreviations}

AI Acoustic index

CEUS Contrast enhanced ultrasound

CPET Cardiopulmonary exercise test

HIIT High-intensity interval training

MBF Microvascular blood flow

MBV Microvascular blood volume

MFV Microvascular flow velocity

MICT Moderate-intensity continuous training

\section{RE Resistance exerciseIntroduction}

Impaired function of the peripheral vasculature becomes increasingly common with advancing age [55], with macro- and microvascular dysfunction often co-existing [54]. Even in the absence of symptomatic peripheral vascular disease, older adults exhibit reductions in whole-limb and microvascular blood flow at rest and in response to exercise, compared to younger adults [15-17]. In terms of the clinical relevance of these deficits in vascular function, it is possible that out with vascular disease per se, they may contribute to the pathogenesis of insulin resistance [32] via impaired delivery of insulin [10, 37], and may also be implicated in the development of hypertension [14]. Another clinical implication of reduced vascular function that has been suggested is its contribution to age-related anabolic blunting and subsequent sarcopenia [67]; the progressive loss of muscle mass and function with advancing age [12]. However, to date, data surrounding this suggestion is equivocal. A number of studies have shown an association between reduced microvascular blood flow and reduced muscle protein synthetic responses to both amino acids [52] and contractile activity [17] — two of the most potent anabolic stimuli [13, 61], in older adults. Conversely, other research, including that by our group has suggested that neither macro- nor microvascular blood flow responsiveness is rate-limiting for muscle protein anabolism based on studies of exercise [48], pharmacological [50] and nutritional enhancement [49] of vascular responses to nutrition. Irrespective, enhanced vascular function offers potential benefit for muscle, cardiovascular and metabolic health $[18,51]$.

Despite the reported benefits of both lifelong exercise and exercise uptake on numerous aspects of physiological function, including central (i.e., cardiovascular
[9]) and peripheral vascular function [56], low adherence to 'traditional', often time-consuming exercise interventions such as those described in common public health guidelines [45], [66] is a limitation to achieving these benefits. In older adults, adherence to this type of exercise training is consistently described as poor, with rates as low as $10 \%$ reported $[30,38,43]$. The rationale for this lack of engagement in older adults is largely akin to those reported across all age-groups, with a perceived lack of time at the fore [6, 39]. Additionally, already poor physical health is also a reported factor in this age-group [42, 44]. High-intensity interval training (HIIT) is an alternative training mode to traditional moderate intensity continuous training (MICT) which may potentially engender increased uptake and adherence due to its time-efficiency (i.e., shorter session duration [33]) and ability to quickly improve factors pertaining to cardiorespiratory health and fitness in both young [4] and older [25] adults. Supporting this notion, a systematic review and meta-analysis of 65 studies concluded that HIIT has the ability to improve cardiorespiratory fitness over both short- $(<12-$ weeks $)$ and longer-term training durations [2]. Although not all studies have demonstrated superiority of HIIT when compared to MICT [19, 21], in terms of absolute improvements in cardiorespiratory fitness, its time-efficient nature is unquestionable [24].

To date, little is known about the effect of HIIT on limb blood flow in older adults and we are unaware of any studies of microvascular blood flow in response to HIIT in any age group. Studies have shown improvement in popliteal artery endothelial function following HIIT in both older and younger adults [46], whilst HIIT in young adults has also been shown to increase expression of endothelial nitric oxide synthase [11]. However, none have examined the effect of HIIT on microvascular blood flow.

Therefore, the primary aim of this study was to assess the effect of 6 weeks' time-efficient HIIT on microvascular responsiveness in healthy older adults.

\section{Methods}

Subject characteristics

Ethical approval (A12092016) was obtained from the University of Nottingham Faculty of Medicine and 
Health Science Research Ethics Committee to recruit adults aged 65-85 years to participate in a trial of 6-week fully supervised HIIT versus a non-intervention control. All participants gave written informed consent to participate. Exclusion criteria included current participation in a formal exercise regime, a $\mathrm{BMI}<18$ or $>30 \mathrm{~kg} \cdot \mathrm{m}^{2}$, active cardiovascular disease, uncontrolled hypertension ( $>160 / 100 \mathrm{mmHg}$ ), diabetes mellitus, family history of early ( $<55$ years) death from cardiovascular disease or known sensitivity to Sonovue ${ }^{\mathrm{TM}}$ contrast agent. The study was registered with clinicaltrials.gov and complied with the 1964 Declaration of Helsinki. Patients were randomised via sealedenvelope.com, using random permuted blocks.

Before baseline testing, all subjects underwent a screening session including a cardiovascular examination by a qualified medical doctor with additional exclusion criteria for further participation as per the American Thoracic Society (ATS)/American College of Chest Physicians (ACCP) guidelines for Cardiopulmonary Exercise Testing (CPET) [64]. A unilateral one-repetition maximum (1-RM) assessment for knee extension was also conducted at this screening session [36] to set the intensity of the RE to be used as our vasodilatory stimulus. At baseline testing, participants underwent measures of skeletal muscle ( $m$. vastus lateralis) microvascular responses to RE by contrast enhanced ultrasound (CEUS) and completed a CPET and resting blood pressure (BP) assessment, as per our previously published protocols [26]. After the 6-week intervention period, all baseline tests were repeated ( $\sim 2 \mathrm{~h}$ after the final HIIT session). Participants were requested to maintain their habitual dietary intake for the duration of the study and to consume a standardised evening meal prior to an overnight fast ( $>10 \mathrm{~h}$, water ad libitum) before each testing session.

\section{Microvascular blood flow}

Using our standard CEUS methods as previously described [41], skeletal muscle microvascular blood flow (MBF) in the $m$. vastus lateralis was measured at rest and in response to a single bout of unilateral RE. In brief, CEUS measures were made using a contrastenabled ultrasound machine (Philips iU22, Phillips Healthcare, Guildford, UK) and a 9-3-mHz probe housed in a custom-made probe-holder secured to the leg with Velcro straps. The probe was secured at midthigh level based on anatomic reference to the inguinal crease and mid-point of the patella. The probe was attached to the participant's thigh for 20 min before CEUS measurements to allow the probe temperature to equilibrate with that of the participant's skin [57] Sonovue $^{\mathrm{TM}}$ (Bracco, Milan, Italy) was used as the microbubble ultrasound contrast agent and was prepared and administered (intravenously into an antecubital fossa vein) as per manufacturer's instructions.

With participants seated on an isometric leg extension machine (ISO Leg extension, Leisure Lines (GB) Ltd., Hinckley, UK), and after a measure of resting BP [25], a single vial of Sonovue ${ }^{\mathrm{TM}}$ was infused at a rate of $2 \mathrm{ml} / \mathrm{min}$ for $1 \mathrm{~min}$ before reduction to $1 \mathrm{ml} /$ min until the syringe was empty. Each vial of Sonovue $^{\mathrm{TM}}$ provided $\sim 4 \mathrm{~min}$ of infusion time, allowing $90 \mathrm{~s}$ of infusion to achieve systemic steady state [41] and a further $2.5 \mathrm{~min}$ to assess MBF.

To determine MBF, microbubbles under the probe which had accumulated during the first $90 \mathrm{~s}$ were destroyed using a brief "flash" impulse of high mechanical index ultrasound from the probe [41]. This flash and the replenishment of contrast agent to the muscle underlying the probe was recorded on two subsequent 30-s cine clips through the probe. Participants were then instructed to perform 6 unilateral isotonic knee extensions at 50\% 1-RM [36]. After this, participants were asked to keep their legs completely still and another set of flash-replenishment cycles were recorded to determine skeletal muscle microvascular responsiveness to the RE bout (Fig. 1).

DICOM video files of the flash-replenishment cycles were analysed using QLAB image quantification software (Version 10, Phillips Healthcare) as previously described [41]. Regions of interest (ROI) were drawn freehand including as much muscle as possible, whilst excluding connective tissue or any large rapid filling vessels (distinct large vessels visibly containing contrast agent within the first $0.05 \mathrm{~s}$ of post-flash recording) and were copied across all cine clips for each participants' visit to ensure consistency of measurements. QLAB then provided a value for the mean acoustic index (AI) (a measure of the echogenicity of the tissue, which increases proportionately to the concentration of the Sonovue ${ }^{\mathrm{TM}}$ [41]) in the ROI for each frame of the cine clip. The mean AI for 
Fig. 1 Schematic representation of study protocol, including assessment days (right) and high intensity interval training (HIIT) (left). Abbreviations: CEUS, contrast enhanced ultrasound; RE, resistance exercise; CPET, cardiopulmonary exercise testing

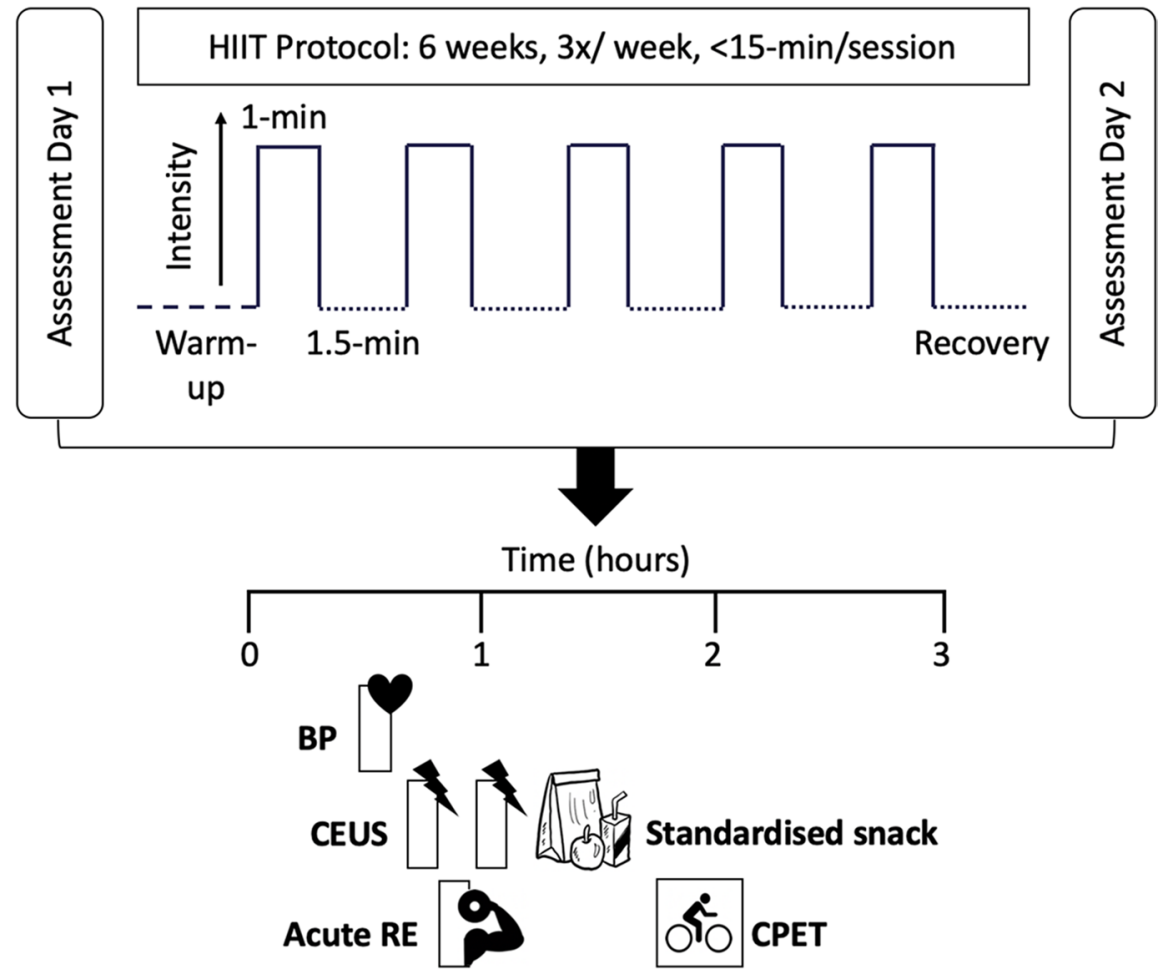

the first 6 frames immediately post-flash was designated the background $\mathrm{AI}$ of the tissue within the ROI and subtracted from all subsequent AI values.

The mean AI data from the pre-RE cine clips were averaged to give one measure of pre-exercise microvascular blood flow which was compared to the mean post-exercise AI data. AI values from both before and after RE were then used to plot curves of AI against time, and determine the exponential function of onephase association using:

$\mathbf{Y}=\mathbf{Y}_{0}+\mathbf{A}\left(1-\mathbf{e}^{-\boldsymbol{\beta} \mathbf{t}}\right)$,

where A denotes the level of the plateau of the graph and is analogous to MBF (volume) within the tissue ROI [57].

\section{Cardiopulmonary exercise testing}

CPET was performed according to ATS/ACCP guidelines [64] using a Lode Corival cycle ergometer (Lode Corival, Lode, Groningen) and inline gas analysis system (ZAN 680, nSpire Health, Colorado, USA) as previously reported [25]. In brief, after 2 min of unloaded cycling, participants were instructed to maintain a cadence of 50-60 revolutions per minute whilst being encouraged to exercise to volitional exhaustion. A Bruce ramp protocol [34, 65] was selected (10-20 W per minute) based on the participant's body weight and self-reported level of habitual physical activity to ensure the CPET was between 8 and $12 \mathrm{~min}$ in duration [8,64]. Anaerobic threshold (AT) was determined using a combination of the V-slope and VE methods [3, 62] by two blinded independent assessors, with disagreement resolved by consensus. As the same ramp protocol was employed per participant for both baseline and post-intervention (or control period) assessments, the maximum wattage achieved during CPET was considered representative of dynamic exercise capacity.

High-intensity interval training (HIIT)

Subjects assigned to HIIT attended the laboratory three times each week for 6 weeks, with each session lasting approximately $15 \mathrm{~min}$ (including a warm-up, 5, 1-min high intensity cycling efforts and a recovery period). The HIIT regime has been described previously [5, 47]. All training sessions were fully supervised and conducted with 12-lead ECG, BP and pulse 
oximetry safety monitoring. After 3 weeks of HIIT (at the end of the $9^{\text {th }}$ training session), participants were asked to rate their perceived exertion on modified Borg scale of $1-10$ [7]. A rating of $\leq 8$ led to a $10 \%$ increase in training intensity for the remaining HIIT sessions [47]. Subjects in the control group attended for pre and post intervention testing sessions only. Compliance for the HIIT sessions was $100 \%$, with all participants attending all of their allocated sessions.

\section{Statistics}

All calculations were performed using GraphPad Prism Version 9.0 (California, USA). Data are presented as mean (SD). Participant demographics at baseline were compared using an unpaired t-test, whilst outcome data were compared using two-way ANOVA (group $\times$ time). Significance was accepted as an alpha of $\mathrm{p}<0.05$. Effect size is reported as Cohen's $d$.

\section{Results}

Participant characteristics

Twenty-five participants were recruited and randomly allocated to either HIIT or the no-intervention control. In one participant assigned to the HIIT group, measurement of MBF was not achieved due to cannula failure leading to contrast extravasation. One participant allocated to the control group did not return for the post intervention visit and was lost to follow-up. Therefore, 23 participants were included in the final analysis. No physiological parameter was different between the two groups at baseline (Table 1).

\section{Anaerobic threshold (AT)}

There was no significant difference in baseline AT between groups $(P=0.37)$ (Table 1$)$. There was however a significant effect of time $(P<0.01)$ and a significant group $\times$ time interaction $(P<0.01)$, with posthoc testing demonstrating a significant increase in AT after the intervention period in the HIIT group only (13.2 (3.4) vs. 15.3 (3.8) $\mathrm{ml} / \mathrm{kg} / \mathrm{min}, P<0.01$; effect size (ES): 0.56), with no change in the control group (15.1 (6.0) vs. 15.2 (6.4) $\mathrm{ml} / \mathrm{kg} / \mathrm{min}, P=0.98$; ES: $0.01)$ (Fig. 2).
Table 1 Participant characteristics, microvascular blood volume, anaerobic threshold and exercise capacity at baseline

\begin{tabular}{lll}
\hline & HIIT $(n=13)$ & CON $(n=12)$ \\
\hline Age $(\mathrm{y})$ & $70(3)$ & $72(6)$ \\
Sex $(\mathrm{male} /$ female $)$ & $5 / 8$ & $7 / 5$ \\
$\mathrm{BMI}\left(\mathrm{kg} / \mathrm{m}^{2}\right)$ & $27.7(2.4)$ & $26.3(2.9)$ \\
$\mathrm{AT}(\mathrm{ml} / \mathrm{kg} / \mathrm{min})$ & $13.2(3.4)$ & $15.1(6.0)$ \\
$\mathrm{W}_{\max }$ & $145(60)$ & $144(63)$ \\
$\mathrm{SBP}$ & $142(15)$ & $130(10)$ \\
DBP & $85(13)$ & $80(10)$ \\
MBV responsiveness & $1.8(0.63)$ & $2.2(1.2)$ \\
\hline
\end{tabular}

Data are presented as mean (SD). Abbreviations: BMI, body mass index; $A T$, anaerobic threshold; $W_{\max }$, maximum wattage achieved during cardiopulmonary exercise testing; $S B P$, systolic blood pressure; $D B P$, diastolic blood pressure; $M B V$, microvascular blood volume (change in response to a single-set of isotonic knee extension exercise)

\section{Exercise capacity}

Used as an indicator of dynamic exercise capacity, there was no significant difference in baseline peak wattage achieved during the CPET $\left(\mathrm{W}_{\text {peak }}\right)$ between groups at baseline $(P=0.96)$ (Table 1). There was a significant effect of time $(P<0.01)$ and a significant group $\times$ time interaction $(P<0.01)$, with post-hoc

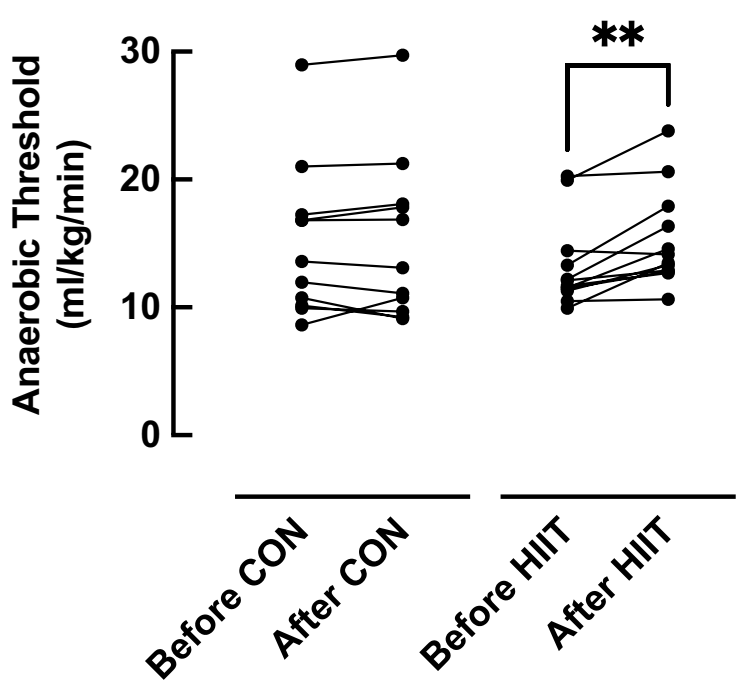

Fig. 2 Anaerobic threshold (AT) before and after 6-week high intensity interval training (HIIT, $n=13$ ) or an equivalent nointervention control period (CON, $n=12)$. Analysis via twoway ANOVA. $* *=p<0.01$ 
testing demonstrating a significant increase in $\mathrm{W}_{\text {peak }}$ after the intervention period in the HIIT group only (145 (60) vs. 159 (59) W, $P<0.01$; ES: 0.25), with no change in the control group (144 (63) vs. 145 (62) W, $P=0.95$; ES: 0.01).

Blood pressure (BP)

There was no significant difference in resting systolic BP (SBP) between the groups at baseline $(P=0.78)$ (Table 1). There was a significant effect of time $(P<0.01)$ and a significant group $\times$ time interaction $(P=0.02)$, with post-hoc testing demonstrating a significant reduction in SBP after the intervention period in the HIIT group only (142 (16) vs. 133 (11) $\mathrm{mmHg}, P<0.01$; ES: -0.67 ), with no change in the control group (130 (10) vs. 128 (10) $\mathrm{mmHg}, P=0.81$; ES: - 0.05) (Fig. 3). There was no significant difference in diastolic blood pressure (DBP) between the groups at baseline $(P=0.78)$ (Table 1), nor was there a significant effect of time $(P=0.27)$ on DBP, or group $\times$ time interaction $(P=0.76)$. The coefficient of variation (CV) for repeated SBP assessments within our laboratory is $2.57 \%$.

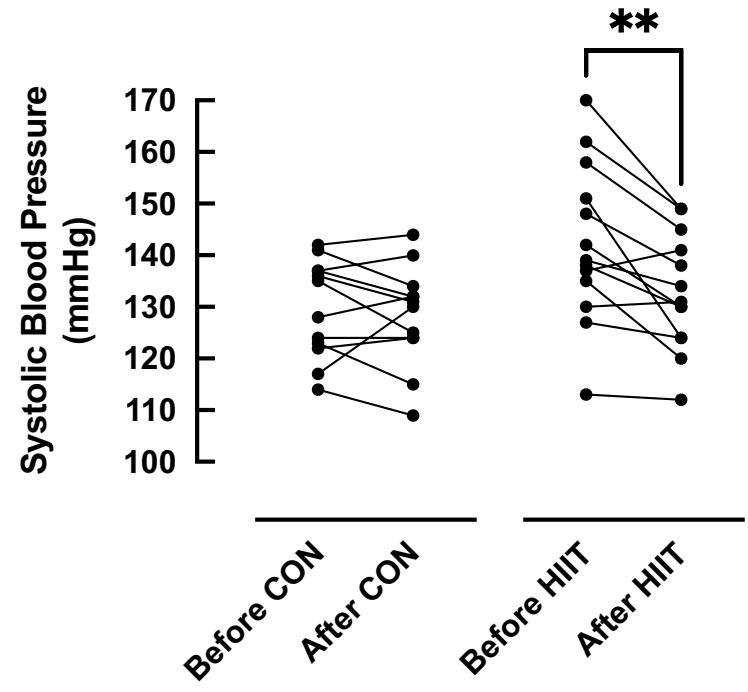

Fig. 3 Systolic blood pressure (SBP) before and after 6-week high intensity interval training (HIIT, $n=13$ ) or an equivalent no-intervention control period $(\mathrm{CON}, n=12)$. Analysis via two-way ANOVA. $* *=p<0.01$
Microvascular blood volume (MBV)

There was no significant difference in MBV responses to a single set of 6 unilateral knee extensions between the groups at baseline $(P=0.24)$ (Table 1$)$. There was a significant effect of time $(P=0.02)$ and a significant group $\times$ time interaction $(P<0.01)$, with post-hoc testing demonstrating a significant increase in MBV responses to $\mathrm{RE}$ after the intervention period in the HIIT group only $(1.8(0.6)$ vs. $2.3(0.8), P<0.01$; ES: $0.64)$, with no change in the control group (2.2 (1.2) vs. 2.2 (1.0), $P=0.94$; ES: -0.12) (Fig. 4). The CV for repeated $\mathrm{MBV}$ assessments within our laboratory is $1.09 \%$.

In assessing the relationship between microvascular blood flow responsiveness and blood pressure, we observed a significant relationship (when the two groups were combined) between baseline SBP and microvascular blood flow responsiveness (change elicited by the bout of $\mathrm{RE})\left(\mathrm{R}^{2}=0.23 ; P=0.02\right.$ (Fig. 5A)), a relationship that was not apparent for DBP $\left(\mathrm{R}^{2}=0.01 ; P=0.60\right)$ or mean arterial pressure $\left(\mathrm{R}^{2}=0.01 ; P=0.18\right)$. Further, based on the reduction in SBP that was observed with HIIT, we sought to explore the relationship between changes in SBP with HIIT, and changes in MBF responsiveness elicited by HIIT. There was no relationship between these changes, $\left(\mathrm{R}^{2}=0.24 ; P=0.10\right.$ (Fig. 5B).

\section{Discussion}

This work demonstrates that 6 weeks, time-efficient HIIT on a cycle ergometer performed 3 times each week elicits improvements in the CRF and SBP of older adults. Further, this HIIT protocol enhanced MBF responsiveness to an acute bout of RE in the functionally important vastus lateralis muscle [60]. To our knowledge, this is the first study to evaluate changes in MBF in response to HIIT, in any age group. We believe these microvascular changes may elicit favourable adaptation to concomitant resistance exercise training, given the known association between vascular dysfunction and skeletal muscle mass/function [18] and as such the effects of multimodal training with both HIIT and RET in the same muscle merit further study.

The underlying reason behind improvements in MBF responsiveness following HIIT may be due to 
Fig. 4 Microvascular blood volume (MBV) responses to an acute bout of resistance exercise (RE; knee extensions) before and after 6-week high intensity interval training (HIIT (C/D), $n=13$ ) or an equivalent nointervention control period $(\mathrm{CON}(\mathbf{A} / \mathbf{B}), n=12)$. Panels $\mathbf{A}$ and $\mathbf{C}$ show microvascular refilling curves before and after the HIIT (C) or control (A) period with arrows representing the increase in MBV (as increase in acoustic intensity (AI)) in response to RE before (grey) and after (black) the HIIT or CON period. Analysis via twoway ANOVA. $* *=p<0.01$
A

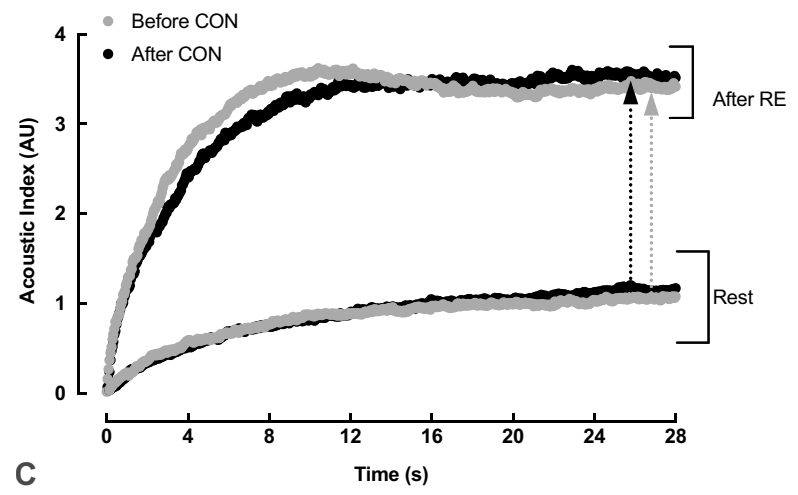

C

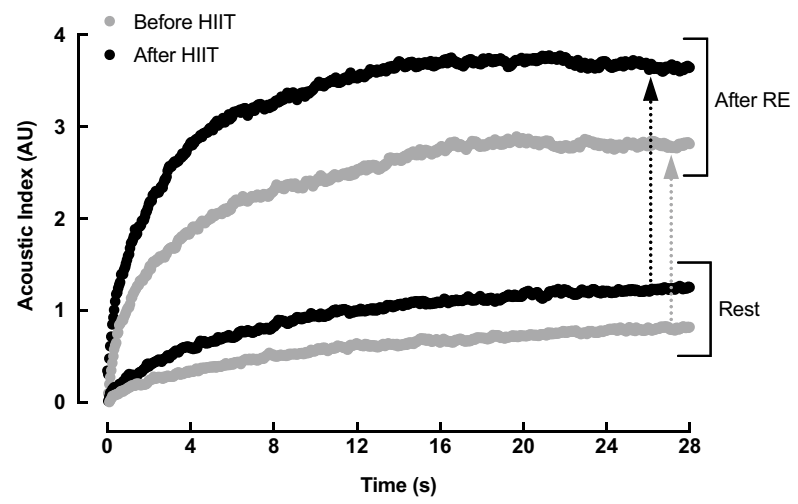

B

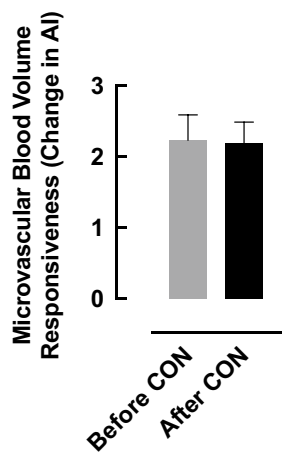

D

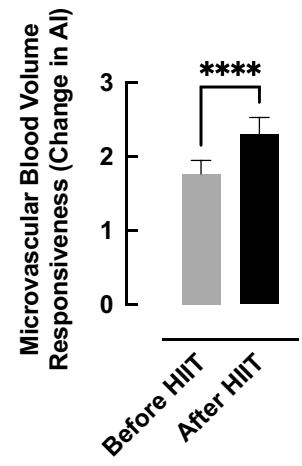

increased capillarization of the muscle [31]. However, previous work comparing the MBF of young and older men with measurements of muscle capillarization via muscle biopsies has shown an agerelated decline in MBF, despite no corresponding reduction in capillarization [28], implying that agerelated impairment in this regard is functional rather than structural. This does not preclude increased capillarization being a mechanism behind our observed increases in MBF responsiveness following HIIT, as angiogenesis has been demonstrated in young [29] and older [23] adults following exercise training, including HIIT [1]. This assertion may also be supported by a previous observational study of 23 healthy middle-aged adults which performed resting CEUS measurements of MBV in the vastus lateralis, before taking biopsies of the same muscle for histological analysis. In this study, MBV significantly correlated with the number of capillary-muscle fibre contacts [63]. In addition, even if increased capillarization is a contributory mechanism for our observed increase in MBV after HIIT, increased capillarization may only be a local effect at the quadriceps as this is the muscle most used in cycle ergometer training [58]. As such, the ability for HIIT to influence aspects of muscle microvascular blood flow in other muscles or indeed tissues (remote to the main contraction site) remains to be tested. Other potential explanations for our HIIT-induced increase in MBV responsiveness, outside of increased capillarisation, include improved vasodilation at the level of the resistance arterioles [59]. Supportive of this suggestion, six-week HIIT has previously been shown to increase the expression of endothelial nitric oxide synthase (the enzyme responsible for the production of the majority of nitric oxide, a potent vasodilator [20]) in young men [11], but there is no data to support this proposition in older adults.

Of note, this study is one of the few to use CEUS to measure muscle microvascular blood flow responsiveness before and after a chronic exercise intervention. Whilst this has been done in both the upper [53] and lower limb [48] in response to RET, this is the first to measure the response following chronic HIIT. Previous chronic training studies using CEUS to measure muscle MBV have, like us, only compared 
A

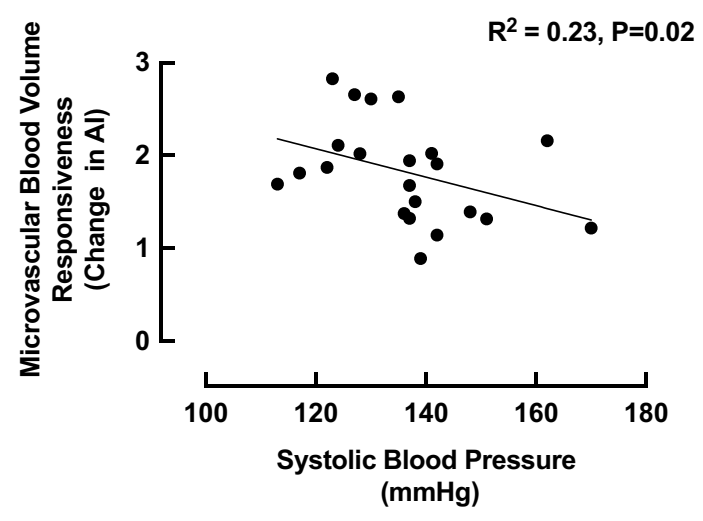

B

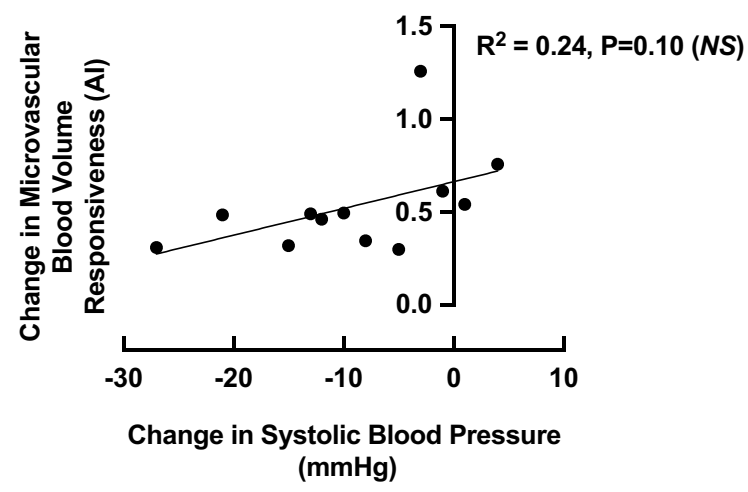

Fig. 5 The relationship between (A) systolic blood pressure (SBP) and microvascular responsiveness (as increase in acoustic intensity $(\mathrm{AI}))$ at baseline $(n=25)$ and $(\mathbf{B})$ change in SBP with high intensity interval training and change in microvascular responsiveness $(n=13)$. Analysis via Pearson's correlation. NS: non-significant

the change in microvascular responsiveness to a stimuli (e.g. feeding) [48] due to CEUS assessment of baseline MBF parameters over a chronic time-period not yet being validated. As such, although we are not able to report on changes in baseline MBF with HIIT, it is interesting that the baseline rested/fasted $\mathrm{MBF}$ of our control group (in the same location based on anatomic reference points) was not different when comparing before and after the intervention period $(p=0.31)$, whilst an increase was observed after HIIT $(p=0.03)$. The primary concerns regarding the chronic application of CEUS is ensuring the same region of the muscle is studied before and after an intervention period, as even if the probe position is marked based on static anatomical landmarks (i.e., the mid-point of the patella), changes in the underlying tissue composition (i.e., due to hypertrophy and/or adipose losses) would alter the measurement region. Baseline to baseline comparisons have been reported in one study; however, this study made no comment as to the validity of this comparison and lacked any non-intervention control group to demonstrate repeatability of measurements [53]. As such, although our findings are suggestive of HIIT-induced improvements in basal MBF in older adults, further work is needed to validate CEUS for this application.

That SBP at baseline was associated with preintervention MBF responsiveness, likely represents improved endothelial function in those with more desirable blood pressure at baseline [27]; however, there was no association between MBF and pre-intervention DBP or MAP and MBF. Despite the correlation between baseline SBP and pre-intervention MBF responsiveness, and HIIT leading to significant improvements in both $\mathrm{MBF}$ and SBP, there was no correlation between the changes in both parameters. This may be due to the presence of both normotensive and hypertensive individuals in this study, with normotensive individuals perhaps being unable to (or indeed needing to) elicit a significant reduction in SBP whilst still making improvements in MBF responsiveness.

In addition, although the clinical significance of HIIT-induced increases in MBV responses to RE has yet to be determined, it may have positive effects on concomitant resistance exercise training, offering a potential strategy to combat sarcopenia and the numerous detrimental consequences of this condition [35]. That the improved responsiveness was observed $72 \mathrm{~h}$ after the final HIIT session, seemingly negates the need for HIIT and RET to perform in close temporal proximity (i.e., in the same session or even on the same day), removing concerns related to session length, fatigue and 'interference' during concurrent exercise [22], and potentially supports a mixedmodality training regime for older adults where HIIT can not only improve CRF and SBP as demonstrated herein, but may also potentially be able to augment RET-induced gains.

One limitation of this study is that it recruited only healthy older adults, excluding those with conditions known to impact vascular function such as obesity and diabetes. As such, these results may not be replicated in patient groups with these conditions. 
However, it may be that those with sub-optimal physiological function can achieve enhanced benefits from our HIIT protocol, as has been seen elsewhere in the literature [40]. This limitation is apparent in a large number of studies exploring physiological parameters/mechanisms, which often employ stringent inclusion/exclusion criteria to reduce participant heterogeneity. Whilst these studies are important to explore new paradigms, we fully support the need for studies of this nature to subsequently be conducted in clinical/at-risk population groups, who are potentially more likely to benefit from these findings.

Acknowledgements The authors would like to acknowledge the contribution of Amanda Gates for her help with data collection for this study.

Funding This research was funded by the Medical Research Council and Versus Arthritis via the MRC-Versus Arthritis Centre for Musculoskeletal Ageing Research (MR/P021220/1). P.J.J. Herrod was supported by a research training fellowship jointly awarded by the Royal College of Surgeons of England and the Dunhill Medical Trust.

\section{Declarations}

Competing interests The authors declare no competing interests.

Open Access This article is licensed under a Creative Commons Attribution 4.0 International License, which permits use, sharing, adaptation, distribution and reproduction in any medium or format, as long as you give appropriate credit to the original author(s) and the source, provide a link to the Creative Commons licence, and indicate if changes were made. The images or other third party material in this article are included in the article's Creative Commons licence, unless indicated otherwise in a credit line to the material. If material is not included in the article's Creative Commons licence and your intended use is not permitted by statutory regulation or exceeds the permitted use, you will need to obtain permission directly from the copyright holder. To view a copy of this licence, visit http://creativecommons.org/licenses/by/4.0/.

\section{References}

1. Alavi SY, Mirdar S. The effect of eight weeks high intensity intermittent training and blood flow restricted on angiogenic markers of muscle in male runners. Ann Appl Sport Sci. 2020;8:2-7. https://doi.org/10.29252/aassjournal.840.

2. Batacan R, Duncan M, Dalbo V, Tucker P, Fenning A. Effects of high-intensity interval training on cardiometabolic health: a systematic review and meta-analysis of intervention studies. $\mathrm{Br} \mathrm{J}$ Sports Med. 2017;51:494-503.

3. Beaver WL, Wasserman K, Whipp BJ. A new method for detecting anaerobic threshold by gas exchange. J Appl Physiol. 1986;60:2020-7. https://doi.org/10.1152/jappl. 1986.60.6.2020.

4. Blackwell J, Atherton PJ, Smith K, Doleman B, Williams JP, Lund JN, Phillips BE. The efficacy of unsupervised home-based exercise regimens in comparison to supervised laboratory-based exercise training upon cardio-respiratory health facets. Physiol Rep. 2017;5:e13390.

5. Boereboom CL, Phillips BE, Williams JP, Lund JN. A 31-day time to surgery compliant exercise training programme improves aerobic health in the elderly. Tech Coloproctol. 2016;20:375-82.

6. Booth ML, Bauman A, Owen N, Gore CJ. Physical activity preferences, preferred sources of assistance, and perceived barriers to increased activity among physically inactive Australians. Prev Med (Baltim). 1997;26:131-7. https://doi.org/10.1006/pmed.1996.9982.

7. Borg GA. Psychophysical bases of perceived exertion. Med Sci Sports Exerc. 1982;14:377-81.

8. Buchfuhrer MJ, Hansen JE, Robinson TE, Sue DY, Wasserman K, Whipp BJ. Optimizing the exercise protocol for cardiopulmonary assessment. J Appl Physiol. 1983;55:1558-64.

9. Carrick-Ranson G, Hastings J, Bhella P, FujimotoN, . The effect of lifelong exercise dose on cardiovascular function during exercise. J Appl Physiol. 2014;116:736-45.

10. Cersosimo E, DeFronzo RA. Insulin resistance and endothelial dysfunction: the road map to cardiovascular diseases. Diabetes Metab Res Rev. 2006;22:423-36. https://doi.org/10.1002/dmrr.634.

11. Cocks M, Shaw CS, Shepherd SO, Fisher JP, Ranasinghe AM, Barker TA, Tipton KD, Wagenmakers AJM. Sprint interval and endurance training are equally effective in increasing muscle microvascular density and eNOS content in sedentary males. J Physiol. 2013;591:641-56. https://doi.org/10.1113/jphysiol.2012.239566.

12. Cruz-Jentoft AJ, Baeyens JP, Bauer JM , Boirie Y, Cederholm T , Landi F , Martin FC , Michel J-P , Rolland Y, Schneider SM, Topinková E, Vandewoude M , Zamboni M , European Working Group on Sarcopenia in Older People. Sarcopenia: European consensus on definition and diagnosis: report of the European Working Group on Sarcopenia in Older People. Age Ageing. 2010;39:412-23. https://doi.org/10.1093/ageing/afq034.

13. Cuthbertson D, Smith K, Babraj J, Leese G, Waddell T, Atherton P, Wackerhage H, Taylor PM, Rennie MJ. Anabolic signaling deficits underlie amino acid resistance of wasting, aging muscle. FASEB J. 2005;19:1-22. https:// doi.org/10.1096/fj.04-2640fje.

14. Dharmashankar K, Widlansky ME. Vascular endothelial function and hypertension: insights and directions. Curr Hypertens Rep. 2010;12:448-55. https://doi.org/10.1007/ s11906-010-0150-2.

15. Dinenno FA, Seals DR, DeSouza CA, Tanaka H. Agerelated decreases in basal limb blood flow in humans: time course, determinants and habitual exercise effects. 
J Physiol. 2001;531:573. https://doi.org/10.1111/J.14697793.2001.0573I.X.

16. Donato AJ, Uberoi A, Wray DW, Nishiyama S, Lawrenson L, Richardson RS. Differential effects of aging on limb blood flow in humans. Am J Physiol Circ Physiol. 2006;290:H2728. https://doi.org/10.1152/ajpheart.00405.2005.

17. Durham WJ, Casperson SL, Dillon EL, Keske MA, Paddon-Jones D, Sanford AP, Hickner RC, Grady JJ, Sheffield-Moore M. Age-related anabolic resistance after endurance-type exercise in healthy humans. FASEB J. 2010;24:4117-27. https://doi.org/10.1096/fj.09-150177.

18. Dvoretskiy S, Lieblein-Boff JC, Jonnalagadda S, Atherton PJ, Phillips BE, Pereira SL. Exploring the association between vascular dysfunction and skeletal muscle mass, strength and function in healthy adults: a systematic review. Nutrients. 2020. https://doi.org/10.3390/nu120 30715.

19. Fisher G, Brown AW, Bohan Brown MM, Alcorn A, Noles C, Winwood L, Resuehr H, George B, Jeansonne MM, Allison DB. High intensity interval- vs moderate intensity- training for improving cardiometabolic health in overweight or obese males: a randomized controlled trial. PLoS ONE. 2015;10: e0138853. https://doi.org/10.1371/ journal.pone.0138853.

20. Förstermann U, Münzel T. Endothelial nitric oxide synthase in vascular disease: from marvel to menace. Circulation. 2006;113:1708-14. https://doi.org/10.1161/CIRCU LATIONAHA.105.602532.

21. Foster C, Farland CV, Guidotti F, Harbin M, Roberts B, Schuette J, Tuuri A, Doberstein ST, Porcari JP. The effects of high intensity interval training vs steady state training on aerobic and anaerobic capacity. J Sports Sci Med. 2015; 14:747-55.

22. Fyfe JJ, Bishop DJ, Stepto NK. Interference between concurrent resistance and endurance exercise: molecular bases and the role of individual training variables. Sports Med. 2014;44(6):743-62. https://doi.org/10.1007/ s40279-014-0162-1.

23. Gavin TP, Ruster RS, Carrithers JA, Zwetsloot KA, Kraus RM, Evans CA, Knapp DJ, Drew JL, McCartney JS, Garry JP, Hickner RC. No difference in the skeletal muscle angiogenic response to aerobic exercise training between young and aged men. J Physiol. 2007;585:231-9. https://doi.org/10.1113/jphysiol.2007.143198.

24. Gillen JB, Gibala MJ. Is high-intensity interval training a time-efficient exercise strategy to improve health and fitness? Appl Physiol Nutr Metab. 2014;39:409-12. https:// doi.org/10.1139/apnm-2013-0187.

25. Herrod PJJ, Blackwell JEM, Boereboom CL, Atherton PJ, Williams JP, Lund JN, Phillips BE. The time course of physiological adaptations to high-intensity interval training in older adults. Aging Med. 2020;3:245-51. https:// doi.org/10.1002/agm2.12127.

26. Herrod PJJ, Blackwell JEM, Moss BF, Gates A, Atherton PJ, Lund JN, Williams JP, Phillips BE. The efficacy of 'static' training interventions for improving indices of cardiorespiratory fitness in premenopausal females. Eur J Appl Physiol 2019: 119. https://doi.org/10.1007/ s00421-018-4054-1
27. Higashi Y, Kihara Y, Noma K. Endothelial dysfunction and hypertension in aging. Hypertens Res. 2012. https://doi.org/ 10.1038/hr.2012.138.

28. Hildebrandt W, Schwarzbach H, Pardun A, Hannemann L, Bogs B, König AM, Mahnken AH, Hildebrandt O, Koehler U, Kinscherf R. Age-related differences in skeletal muscle microvascular response to exercise as detected by contrast-enhanced ultrasound (CEUS). PLOS ONE. 2017;12: e0172771. https://doi.org/10.1371/journal.pone. 0172771 .

29. Hoier B, Nordsborg N, Andersen S, Jensen L, Nybo L, Bangsbo J, Hellsten Y. Pro- and anti-angiogenic factors in human skeletal muscle in response to acute exercise and training. J Physiol. 2012;590:595-606. https://doi.org/10. 1113/jphysiol.2011.216135.

30. Jefferis BJ, Sartini C, Lee I-M, Choi M, Amuzu A, Gutierrez C, Casas JP, Ash S, Lennnon LT, Wannamethee SG, Whincup PH. Adherence to physical activity guidelines in older adults, using objectively measured physical activity in a population-based study. BMC Public Health. 2014;14:382. https://doi.org/10.1186/1471-2458-14-382.

31. Jensen L, Bangsbo J, Hellsten Y. Effect of high intensity training on capillarization and presence of angiogenic factors in human skeletal muscle. J Physiol. 2004;557:57182. https://doi.org/10.1113/jphysiol.2003.057711.

32. Julius S, Gudbrandsson T, Jamerson K, Andersson O. The interconnection between sympathetics, microcirculation, and insulin resistance in hypertension. Blood Press. 1992;1:9-19.

33. Jung ME, Bourne JE, Beauchamp MR, Robinson E, Little JP. High-intensity interval training as an efficacious alternative to moderate-intensity continuous training for adults with prediabetes. J Diabetes Res. 2015;2015: 191595. https://doi.org/10.1155/2015/191595.

34. Kaminsky LA, Whaley MH. Evaluation of a new standardized ramp protocol: the BSU/Bruce Ramp protocol. J Cardiopulm Rehabil. 1998;18:438-44.

35. Lang T, Streeper T, Cawthon P, Baldwin K, Taaffe DR, Harris TB. Sarcopenia: etiology, clinical consequences, intervention, and assessment. Osteoporos Int. 2010. https:// doi.org/10.1007/s00198-009-1059-y.

36. Levinger I, Goodman C, Hare DL, Jerums G, Toia D, Selig S. The reliability of the 1RM strength test for untrained middleaged individuals. J Sci Med Sport. 2009;12:310-6. https://doi. org/10.1016/j.jsams.2007.10.007.

37. Lindner JR. Cause or effect? Microvascular dysfunction in insulin resistant states. Circ Cardiovasc Imaging. 2018;11: e007725. https://doi.org/10.1161/CIRCIMAGING.118. 007725.

38. Luzak A, Heier M, Thorand B, Laxy M, Nowak D, Peters A, Schulz H, Group, for the K-S. Physical activity levels, duration pattern and adherence to WHO recommendations in German adults. PLoS One. 2017;12:e0172503. https:// doi.org/10.1371/journal.pone.0172503.

39. Macera CA, Cavanaugh A, Bellettiere J. State of the art review: physical activity and older adults. Am J Lifestyle Med. 2017;11:42-57. https://doi.org/10.1177/1559827615 571897.

40. Martin-Smith R, Cox A, Buchan DS, Baker JS, Grace F, Sculthorpe N. High intensity interval training (HIIT) improves cardiorespiratory fitness (CRF) in healthy, 
overweight and obese adolescents: a systematic review and meta-analysis of controlled studies. Int J Environ Res Public Health 2020: 17. https://doi.org/10.3390/IJERP H17082955

41. Mitchell WK, Phillips BE, Williams JP, Rankin D, Smith K, Lund JN, Atherton PJ. Development of a new Sonovue contrast-enhanced ultrasound approach reveals temporal and age-related features of muscle microvascular responses to feeding. Physiol Rep 2013: 1. https://doi.org/ 10.1002/phy2.119

42. Moschny A, Platen P, Klaaßen-Mielke R, Trampisch U, Hinrichs T. Barriers to physical activity in older adults in Germany: a cross-sectional study 2011. https://doi.org/10. 1186/1479-5868-8-121

43. Nawrocka A, Mynarski W, Cholewa J. Adherence to physical activity guidelines and functional fitness of elderly women, using objective measurement. Ann Agric Environ Med. 2017;24:632-5. https://doi.org/10.5604/12321966.1231388.

44. Newson RS, Kemps EB. Factors that promote and prevent exercise engagement in older adults. J Aging Health. 2007;19:47081. https://doi.org/10.1177/0898264307300169.

45. NHS, 2018. Physical activity guidelines for older adults [WWW Document]. https://www.nhs.uk/live-well/exercise/physical-activityguidelines-older-adults/. Accessed 11 Aug 2019.

46. O’Brien MW, Johns JA, Robinson SA, Bungay A, Mekary S, Kimmerly DS. Impact of high-intensity interval training, moderate-intensity continuous training, and resistance training on endothelial function in older adults. Med Sci Sports Exerc. 2020;52:1057-67. https://doi.org/10.1249/MSS. 0000000000002226.

47. Phillips B, Kelly B, Lilja M, Ponce-González JG, Brogan RJ, Morris DL, Gustafsson T, Kraus WE, Atherton PJ, Vollaard NBJ, Rooyackers O, Timmons JA. A practical and time-efficient high-intensity interval training program modifies cardio-metabolic risk factors in adults with risk factors for type II diabetes. Front Endocrinol (Lausanne). 2017;8:1-11.

48. Phillips BE, Atherton PJ, Varadhan K, Limb MC, Wilkinson DJ, Sjøberg KA, Smith K, Williams JP. The effects of resistance exercise training on macro- and micro-circulatory responses to feeding and skeletal muscle protein anabolism in older men. J Physiol. 2015;593:2721-34. https://doi.org/ 10.1113/JP270343.

49. Phillips BE, Atherton PJ, Varadhan K, Limb MC, Williams JP, Smith K. Acute cocoa flavanol supplementation improves muscle macro- and microvascular but not anabolic responses to amino acids in older men. Appl Physiol Nutr Metab. 2016;41:548-56. https://doi.org/10.1139/apnm-2015-0543.

50. Phillips BE, Atherton PJ, Varadhan K, Wilkinson DJ, Limb M, Selby AL, Rennie MJ, Smith K, Williams JP. Pharmacological enhancement of leg and muscle microvascular blood flow does not augment anabolic responses in skeletal muscle of young men under fed conditions. Am J Physiol Metab. 2014;306:E168-76. https://doi.org/10.1152/ajpendo.00440. 2013.

51. Pizzimenti M, Meyer A, Charles AL, Giannini M, Chakfé N, Lejay A, Geny B. Sarcopenia and peripheral arterial disease: a systematic review. J Cachexia Sarcopenia Muscle. 2020. https://doi.org/10.1002/jcsm.12587.

52. Rasmussen BB, Fujita S, Wolfe RR, Mittendorfer B, Roy $\mathrm{M}$, Rowe VL, Volpi E. Insulin resistance of muscle protein metabolism in aging. FASEB J. 2006;20:768-9. https://doi. org/10.1096/fj.05-4607fje.

53. Russell RD, Hu D, Greenaway T, Blackwood SJ, Dwyer RM, Sharman JE, Jones G, Squibb KA, Brown AA, Otahal P, Boman M, Al-Aubaidy H, Premilovac D, Roberts CK, Hitchins S, Richards SM, Rattigan S, Keske MA. Skeletal muscle microvascular-linked improvements in glycemic control from resistance training in individuals with type 2 diabetes. Diabetes Care. 2017;40:1256-63. https://doi.org/ 10.2337/dc16-2750.

54. Scioli MG, Bielli A, Arcuri G, Ferlosio A, Orlandi A. Ageing and microvasculature. Vasc. Cell. 2014;6:19. https://doi. org/10.1186/2045-824X-6-19.

55. Shammas NW. Epidemiology, classification, and modifiable risk factors of peripheral arterial disease. Vasc Health Risk Manag. 2007;3:229.

56. Shibata S, Fujimoto N, Hastings JL, Carrick-Ranson G, Bhella PS, Hearon CM, Levine BD. The effect of lifelong exercise frequency on arterial stiffness. J Physiol. 2018;596:2783-95. https://doi.org/10.1113/JP275301.

57. Sjøberg KA, Rattigan S, Hiscock N, Richter EA, Kiens B. A new method to study changes in microvascular blood volume in muscle and adipose tissue: real-time imaging in humans and rat. Am J Physiol Circ Physiol. 2011;301:H450-8. https://doi.org/10.1152/ajpheart.01174. 2010.

58. So RC, $\mathrm{Ng} \mathrm{JK}, \mathrm{Ng}$ GY. Muscle recruitment pattern in cycling: a review. Phys Ther Sport. 2005;6:89-96. https:// doi.org/10.1016/J.PTSP.2005.02.004.

59. Socha MJ, Segal SS. Microvascular mechanisms limiting skeletal muscle blood flow with advancing age. J Appl Physiol. 2018;125:1851-9. https://doi.org/10.1152/jappl physiol.00113.2018.

60. van der Zwaard S, Weide G, Levels K, Eikelboom MRI, Noordhof DA, Hofmijster MJ, van der Laarse WJ, de Koning JJ, de Ruiter CJ, Jaspers RT. Muscle morphology of the vastus lateralis is strongly related to ergometer performance, sprint capacity and endurance capacity in Olympic rowers. J Sports Sci. 2018;36:2111-20. https://doi.org/10.1080/02640414.2018. 1439434.

61. Wackerhage H, Schoenfeld BJ, Hamilton DL, Lehti M, Hulmi JJ. Stimuli and sensors that initiate skeletal muscle hypertrophy following resistance exercise. J Appl Physiol. 2019;126:30-43. https://doi.org/10.1152/japplphysiol. 00685.2018 .

62. Wasserman K, Whipp BJ, Koyal SN, Beaver WL. Anaerobic threshold and respiratory gas exchange during exercise. J Appl Physiol. 1973;35:236-43.

63. Weber M-A, Krakowski-Roosen H, Delorme S, Renk H, Krix M, Millies J, Kinscherf R, Künkele A, Kauczor H-U, Hildebrandt W. Relationship of skeletal muscle perfusion measured by contrast-enhanced ultrasonography to histologic microvascular density. J Ultrasound Med. 2006;25:583-91. https://doi.org/10.7863/jum.2006.25.5. 583.

64. Weisman IM, Marciniuk D, Martinez FJ, Al E. ATS/ACCP Statement on cardiopulmonary exercise testing. Am J Respir Crit Care Med. 2003;167:211-77.

65. Will PM, Walter JD. Exercise testing: improving performance with a ramped Bruce protocol. Am Heart J. 1999;138:1033-7. 
66. World Health Organisation, 2015. WHO Global recommendations on physical activity for health [WWW Document]. WHO. https://www.who.int/dietphysicalactivity/publications/ 9789241599979/en/. Accessed 28 March 2019.

67. Zempo H, Isobe M, Naito H. Link between blood flow and muscle protein metabolism in elderly adults. J Phys Fit Sport Med. 2017;6:25-31. https://doi.org/10.7600/ jpfsm.6.25.
Publisher's note Springer Nature remains neutral with regard to jurisdictional claims in published maps and institutional affiliations. 